\title{
Illegal Migration Causes and Impacts Among Returnees Women from Middle East Countries: The Case of Woliso Town, South-west Showa Zone Oromia Region, Ethiopia
}

\author{
Alemneh Birhanu \\ Department of Social Work, College of Social Science and Humanities, Ambo University, Ambo, Ethiopia
}

\begin{abstract}
The main aim of this research study was to investigate the causes of illegal migration and its impacts in the returnees who are living in Woliso town. To achieve these objectives, qualitative methods and Semi-structured in depth interviews were held with a total of 25 women participants. Descriptive phenomenology was the approach employed for conducting this study. The purposive sampling technique was used to select 25 returnees of illegal emigrant from Middle East countries. The Primary information was collected mainly from the migrants, Labour and Social affairs office. Phenomenological method of analysis for study was used to analyze the data obtained from the participants. The findings of the study revealed that there are a variety of contributory factors that led to the emergence of migrant women from Ethiopia to Middle East countries. The result showed that the major factors contributing to the migration and vulnerability of Ethiopian women to illegal emigration are lack of employment, poverty, lack of prospects, the search for better opportunities and income to support themselves and their families and economic insecurity as the probable cause of this migration. The finding further indicated that Illegally emigrated women from Ethiopia are exposed to various forms of abuse and exploitation such as prohibition of contact with family members, long working hours, labor exploitation, denial of rest and leave, denial of food, sexual harassment and rape, beatings and imprisonment in the country of destination. In general, the results of the study show that those returnees have needs that call for greater attention to be given as the available services and service providers need to be attentive to their needs and the need to expand the types and number of services provided for these women.
\end{abstract}

Keywords: illegal immigration, pushing factors, domestic workers, physical and sexual abuse

DOI: $10.7176 / \mathrm{JCSD} / 52-03$

Publication date:October $31^{\text {st }} 2019$

\section{Introduction}

\subsection{Background of the Study}

Illegal immigration is defined according to the United States Immigration Services as: "Immigration across national borders in a way that violates the immigration law of the destination country(UNDP, 2009). Illegal emigration of people, particularly women, is increasingly becoming an issue of global concern. One of the largest current international migration flows is Ethiopian women migrating to the Middle East as domestic workers, which also often occurs through trafficking (Fernandez, 2013 and Endeshaw et al., 2006). In the case of Ethiopian women going to the Middle East, the initial migration decision is made by their own free will. They are, however, given misinformation regarding the position and circumstances waiting for them in the host country (Seifeselassie and Jones et al., 2014).

Illegal emigration of female from Ethiopia, especially to countries in the Middle East, is recognized as unemployment, social, economic and political problem (Fernandez, (2013). The top destinations are Lebanon, Saudi Arabia, Yemen, and the United Arab Emirates (Tsehay, 2011).

The majority of Ethiopian migrants living in the Middle East came up from different part of rural and urban areas of Ethiopia (IOM, 2014). Women who migrate to the Middle East will often do so using a tourist visa and claim to be travelling for a religious pilgrimage.

Most of the Ethiopian women who move irregularly to middle east countries and working as domestic workers in the Middle East are described as suffering inadequate working conditions, physical and sexual abuse, and human right violation, in some cases even death (Anbesse et al., 2009 and ILO 2011). what's more, Women have described having their passports taken away so they cannot leave, being expected to work 24 hours per day, and not being able to have contact with other Ethiopians (IOM 2014).

The study by Anbesse et al., (2009) described how these conditions lead to 'social defeat' of the migrant women. From 1999-2005 the Quarantine Office of the Addis Ababa International Airport reported 129 female bodies returned from Jeddah, Dubai, and Beirut. In all cases the cause of death was determined to be suicide (IOM, 2014). The study conducted by Anbesse et al. (2009) on returnees from the Middle East to Ethiopia arose due to the observations of the number of return migrants seeking professional psychiatric help. The authors suggest that this is just the tip of the iceberg of mental disorders experienced by female migrants, and it is an area of concern. 


\subsection{Statement of the Problem}

The migration problem in the Horn of Africa has been substantial in the past four decades (Spaan \& Van Moppes, 2006). Ethiopia is one of the most populous countries in Africa estimated with a total population of 108,386,391 (CIA, 2018). Ethiopia has experienced political instability, war, famine, and economic hardship over the course of its history.

A recent study showed that most victims of external illegal immigrants of Ethiopian are women between 20 and 35 years old. Children less than eighteen years old and as young as thirteen are also illegally emigrated, usually with ratified documents to certify their age (Emebet, 2010). Official Ethiopian migration records show that the number of female migrants has been steadily increasing. Labor exploitation is also often related to the drafting and implementation of the employment contact the condition of work. The payment of salary and the termination of the contact often illegal emigration arrived in the destination country without an employment contact, where they may be forced to sign a contact written in Arabic after their arrival (Emebet, 2010).

Illegal emigration of women from Ethiopia, especially to country in the Middle East, is recognized as a significant problem (Tsehay, 2011 and Philippe Fargues and Nasra, 2017). Although official Ethiopian migration records show that the number of female migrants has been steadily increasing, the causes and consequences of the problem remains largely undocumented. Thus, the objective of this study is to assess the causes of illegal emigration of women and its consequences in Woliso town of South-West Showa zone. Therefore, this research fills these gaps and provides full information by explaining the causes and consequence of women illegal emigration in the town.

\subsection{Objectives of the Study}

The all purpose of this study was to assess the causes of illegal emigration of women and its consequences in Woliso town of South-West Showa zone.

\section{Research and material}

\subsection{Study Design and Method}

The research method that was employed during this study was cross sectional qualitative research approach. The justification for using method is that the research study was conducted in a single point in a time and was largely based on subjective interpretation of the participants. As Nick (2010) elaborated, qualitative research tends to be interpretive and seeks to understand a phenomenon in its context in greater depth. Moreover, it seeks to elucidate the nature of social practices, relationships and beliefs along with the meaning of human experiences from the participants' point of view. This research study was carried out in line with scientific method of social work research. Exploratory study in qualitative method is advantageous in giving opportunity for participants to respond in their own words. Moreover qualitative research explain how it may be useful for exploring "why" rather "how many". Thus since the study used exploratory qualitative approach, substantial data were collected, analyzed and interpreted in relation to the research questions and objectives (Finlay, 2009).

\subsection{Sampling Techniques and Sample Size}

During the study, purposive sampling technique was used. This was because the sampling technique allows the researcher to select the sample for study. In purposive sampling technique, the researcher may have prior knowledge that indicates that a particular group is important to study or to select those participants. This sampling technique also enables a researcher to gain an initial understanding of the situation, and to identify and differentiate the needs of one or more relevant groups. It produces a sample where the included groups are selected according to specific characteristics that are considered to be important as related to vulnerability and group differences which can be compared, contrasted and a variety of experiences can be summarized (Cresswell, 2014).

From this sampling technique, the researcher used purposive sampling technique in an attempt to select informant returnees subjectively based on the purpose of the study. The sample size for this study was 20 illegal emigrant returnees in which 15 of them participated in an in- depth interview and five participated in focus group discussion. The remaining four key informants were selected from south-west showa zone women and child affairs and labor and social affairs bureau in Woliso town. A total of 24 participants were involved in the study.

According to Creswell (2014), the sample size of qualitative research is largely determined by theoretical data saturation especially at a point during data collection stage where new participants do not any longer bring new data or additional insights to the research questions. That was exactly what we used, because we stopped recruiting new participants after we concluded that no new information was being provided by the participants during data collection.

\subsection{Instrument of Data Collection tools}

In this study qualitative data collection tools were utilized. The main data collection tools that were used are: in- 
depth interview, focus group discussion, key informant interview to collect data. Data was collected using a semistructured in-depth interview with the research participants. This type of instrument was chosen for this particular study because it was believed to best facilitate a way in which the women could provide detailed accounts of their experiences. This is because such an instrument help to make sure the women spoke of issues related to the topic that the researcher is investigating while also giving enough freedom for detailed and holistic description of the phenomenon.

In this study, a focus group discussion was used to collect qualitative data and accordingly an open ended focus group discussion guide was prepared and utilized to gather data about the individual's as well as group's perspectives to obtain deeper understanding of the cause and consequences of the participants. This focus group discussion consisted of one groups with five discussants, and the discussion took 1.30 hour of the discussion time.

Key informant interview was also used to gather qualitative data from other personnel who have professional background related to the area, in which four participants were engaged, two personnel from South West Shewa Zone Women and Children Affairs Bureau and two personnel from South West Shewa Zone labor and social affairs bureau. The research was conducted with these four key informant interviews with the assumption that those interviewed have a profound knowledge on the life situation of illegal immigrant returnees. It helps researchers to get supplement data generated from the participants and also get an additional insight into the phenomenon from view point of the experts (Kothari, 2004).

\subsection{Methods of Data Analysis}

In this study, qualitative data analysis method was used. Accordingly, we employed thematic data analysis procedure delineated by Braun and Clarke (2006).

\subsection{Ethical Considerations}

In conducting this study, the following ethical issues were considered in the all stages of the research process. Explained the significant and objective of the study were given to the respondents. confidentiality and anonymity were insured. concern for the protection and welfare of subject were communicated before participation, and respondents participated voluntary with no partially for participating. They were informed that they have a right not to answer any part or whole of question if they feel so and that they were free to withdraw from the study at any time. They were also informed that the information they were providing would be kept in state of confidentiality that means they will not be disclosed to any other third party.

\section{Result and discussion}

This part presents the findings of the study. The translated Meaning Units were related to the research questions and then developed in to categories accordingly.

Description of the Study AreaThe data were collected from Woliso town south-west showa zone, Oromia region and found out of the cases of and consequence of illegal immigration of women. Woliso is a town and separate Woreda in central Ethiopia located in the Debub Mirab Shewa (South West Shewa) of Oromia Region. The town is $114 \mathrm{~km}$ southwest of Addis Ababa. Woliso town has seven administrative Kebeles. Dej. Geresu Duki Comprehensive Secondary School, Oromia Institute of Water Technology, Woliso's Poly Technic College, Ambo University Faculty of Business and Economic Woliso-campus and other private institutes and colleges are located in Woliso.

In Woliso, there is a natural hot-spring water which makes the town one among the leading tourism heritages in Ethiopia. The town has an amazing view from Meja hill a volcanic mountain, also on top of Tulluu Majaa in Afan Oromo, situated at the center of the town; one can be able to view 360 degree. A Crater Lake Wonchi, the most beautiful lake in Africa, is only 32 kilometers away from Woliso. The town is the largest and administrative town in South West Shewa Zone. The 2007 national census reported a total population for Woliso town to be 59,685 people of whom 18,880 were men and 18,998 were women.

Woliso town is characterized by mutually contributing socio-economic problems. Ever increasing rate of population pressure from excessive immigration, income shortage, urban poverty, unemployment and strikingly high and ever increasing HIV/AIDS prevalence rate are among the town's socio-economic problems (Source: officer from $B W C A$ ). According to the information provided by South West Shewa Zone Bureau of Women and Children Affairs, there is less effort and commitment being exerted by government and nongovernmental organizations to deal with the problems facing returnees.

\subsection{Causes of Illegal Emigration}

Victims of illegal immigration interviewed for this study identified economic reasons as the major pushing factors for their migration. The purpose of their migration, in most cases is to earn better wages so they can send remittances home of their families Ethiopia. One returnee from Beruit stated:

"I am in the family. My father was taking care of us and life was relatively good. However, when my father 
died the family faced serious financial problems and we worried about our long term survival. We agreed that I should use the money we received as severance pay from my father employer to migrate and work in one of the Middle East countries. We were hoping that I would to able to send money home to support the family."

Another returnee from Dubai identified the separation of parent and subsequent financial problems in the family as the major reason driving her migration.

"She said, My family had a good life. After sometimes my parents fell in to disagreement.

Up on their separately my father, who was the bread winner of the family stopped supporting us. Since I was eldest of five children, I decide to work abroad to support

My mother, sister and brother."

Sometimes, girls whose families are financially better to decide to travel and work broad in search of self sufficiency and better standard of living. One returnee from Lebanon said:

"My parents have good jobs. My father paid the three thousand birr to the broker without having to borrow money. There is no problem in houses. The only reason I want to Lebanon was to improve my life."

Another respondent identified failure in education and absence of opportunity of financially support themselves as driving causes for their migrants To work abroad. One returnee from Beirut stated that, "I wanted to go to the Middle East because I failed $9^{\text {th }}$ grade. I was very frustrated. I wanted to save money so that I could return and start business here."Girls who drop out of school for reasons other than educational performance

also consider work a broad as a path to economic and social success. One returnee from kwait stated, "I wanted to migrate to the kwait after I interned school in $11^{\text {th }}$ grade due to marriage and pregnancy."

\subsection{Problems the Returnees Encountered During Their Course of Illegal Emigration}

Many women who work in Middle Eastern countries illegally emigrated through their families in Ethiopia. In some cases families with children living a broad fraudulently claim that their children will help victims adjust to life abroad.

"Women introduced me to a broker and promised me that her daughter, who lived in Lebanon, would help me once I arrived. When arrived in Lebanon, I met with the daughter, she has no idea that her mother had helped to arrange my travel or sent me to her. She was very disappointed any angry with her mother. She asked me why her mother had sent me to Lebanon to suffer after having read all latter she wrote about the terrible conditions she was facing in Beirut. I would never have trusted the broker it was not for the stories the mother told me abouther daughters, life."

Though facilitators present themselves as concerns individuals, they actually receive commission from brokers for each success fully, illegally emigrated women. The story of returnee from Beirut interviewed for this report sheds more light on the role of the facilitator in the recruitment process:

"I had just completed high school with poor results and was unemployed, at the Lideta Miriam ceremony organized by my mother, a women I did not know came to our house with a neighbor. The women told my mother about girls of my age who live in Beruit and send money to the parents. She spoke of a close friend whose daughter lives a very good life and helps her family, and offered to talk

together friend about possibility of my working in Beirut the woman took my mother and me to the woman's house a few days later talk about the kind of more I am point to do in Beruit and the money we have to pay her. After the first meeting I met the woman only a few times. My mother paid her a total of three thousand birr."

As described above, most brokers recruit women in an informal manner using a facilitator. The facilitator's first task is to identify a woman who could be convinced to seek the help of brokers. The facilitator is friends of her family and suggested the possibility of employment in a foreign country as a means of dealing with the family's problems. The story of a returnee from the Beirut described this mode of recruitment:

"I was out of work and lived my mother's house. My family was facing financial problems since my father left us. Also my mother was employed; she could not earn enough to support my four younger brother and sisters. A neighbor who works as a broker for house maid told my mother about a woman who makes arrangement for employment in Lebanon. Our neighbor advised us not to miss the chance to talk to her, even if I decided not to abroad. A few days later he arranged for a meeting at her house."

As shown in above case the meeting with the broker may take place at his or her home. The facilitator, who has the tress of the victim, convenes her that the payment set by the broker is fair. The total amount and manner of payment depends on a number of factors. Returnees interviewed for this paid $\mathrm{b} / \mathrm{n}$ two and eight thousand Birr. The highest amount, eight thousand birr, was paid by returnees from Dubai while the lower paid by Beirut.

In many cases, parents finance their children's migration by borrowing money from illegal loan sharks at exorbitant interest its. One returnee from Beirut stated:

"Since my family was not in a position to pay the six thousand Birr the broker asked, my mother borrowed the money from a man who paves loans at interest.

My mother paid more than two thousand birr in interest."

Contacts of employment are also altered with auto the employee. This occurs even when the changes relate to 
basic terms of the contract such as the identity of the employer, the place of work and the type of work a victim of such act stated:

"The agency sent me to work for an employs other than the named in my contract.

My name in my pass part is different from the name in a document kept by the employer who believes that I have cheated with a fake passport. Later on I learned that the agency apparently witched my name internationally to favor another person..." (Recent returnee from Dubai, 2013)

As illustrated from the above words of the returnees' women who sign a contract to work in an urban house hold may be sent to employers in deep rural locations without their consent. Agencies also transfer their domestic workers to another agent by attaining and transferring the documents of the victims. One returnee stated that "the agent agreed with another agent and transferred my passport and other documents. In effect I was sold."

Salaries may never be paid to victims; for example, one returnee from Dubai was forced to return to Ethiopia without receiving her salary or the last seven months of her employment. Employers may take advantage of the power imbalance between themselves and the employee to deny payment of salary.

\subsection{Problems Encountered by Returnees at their Place of Emigration}

Domestic workers reportedly work between nine and nineteen hours a day with very limited rest throughout the day. A disturbingly most number of respondents for this study and previous studies reported similar cases of exploitation, bordering on enslavement. A Returnee from Dubai described her typical day as follows:

"I wake up at six in the morning and work until ten in the evening (Sixteen hours) with any rest. I sometimes work longer house when I must serve posts who visit late at night and stay until three in the morning. But no matter how late I work the previous night, I must begin work by six in the morning the next day."

According to this explanation, in many cases, the victims are not allowed to leave the employer's compound except when it is part of their household chares.

Those women illegally emigrated to Middle Eastern countries suffer from recurrent physical and emotion abuse by employers. According to returnees, employers resort to intimidation and physical abuse routinely as a way of reviving the attention of an over worked house maid as punishment for minor mistakes. One respondent from Kuwait stated:

"The madam wife shouted at me not to touch any of her children. I was not even allowed to take meals with cups, spoons or trays that the family used. She had set aside a spoon, a cup and a tray that I could use to have my meals which she kept separately in the bathroom..."

According to this study four of five of returnees reported sexual abuse in work place. The most common forms of sexual abuse on house maid are verbal sexual harassment and sexual contact. One return from Beruit stated that, "the husband come to the kitchen while his wife sleep and cares me and holds my breasts."

About three of five involved in the study also reported instances of rape with male employers were identified as the usual sexual abusers and female employers were the perpetrators or of sexual abuse.

\subsection{Attitudes of Respondents and Returnees towards Illegal Emigration of Women}

As the data gained from participants, majority of the participants stated that illegal emigration is very bad, even if some individual benefited from it.

Majority of whom interviewed returnees stated that illegal emigration is very bad by explaining many difficulties that encountered them and that they saw on their friends and other women. This includes work load, suicide in the forms of hanging, jumping from buildings, and using fire arms, physical and emotional abuse.

Connecting with the above explanations some of the returnees of illegal emigration stated that the communities have very bad attitudes toward them. For instance one returnee from Beirut stated: People called us, those illegal emigrants were prostitute during they were working abroad" and they are doubt of different diseased such as HIV/AIDS. Besides are being isolated from different previsions of social services. But I had gathered every individual attempted to get me in the form of manage thus. I think this act negatively affects the social structure." One returnee stated family and government have favorable attitude towards them by saying:

" Since I started different business activities and participated in the development of the town, the buddy of government and members of the community gave me good reception, even if it is not as expected."

All of returnees interviewed agreed that, the attitudes of destination country, family community towards them was very bad.

\section{Discussion of the Findings}

This study found that some of the socio-economic variables have been a significant influence on females illegal migration to Middle East countries. This study endeavored to succeed factors that affect women to be a part of illegal migration and its consequence at Woliso town in south-west showa Zone.

The research showed that the participants who were partook in illegal immigration identified economic reasons as the major pushing factors for their migration. According their expression, the purpose of their migration, 
in most cases is to earn better wages so they can send remittances home of their families. immigrant Women are hoping to send money in order to support their family." This finding is consistent with other findings (Andersson, (2014 and Emerta Asminew et al., 2010).

From the interview, The participants identified that the failure in education and absence of opportunity of financially support themselves could be a driving sources for their migration to work out of the country. This idea was prop up by (Docquier \& Marfouk, 2006 and Abiy, 2010), Most illegal emigration are either illiterate or have only elementary level education.

The finding confirmed that Those women illegally emigrated to Middle Eastern countries suffer from recurrent physical and emotion abuse by employers. The women have experienced, usually a combination of, various forms of violence by there employer including physical, sexual, psychological abuses as that have been shown in studies at a number of research which were conducted (Jones et al., 2014). However, the immigration women described and discussed in length were the abuse acts that were more physical even though they had discussed almost all sorts of violence. This might indicate the fact that other types of violence were more hurtful and thus harder to talk about as described by their employers.

The focus group discussion findings bear out that The most prevent forms of abuse and Exploitation faced by women working as house maids in Middle Eastern countries are over work, sexual abuse conferment in just it and the physical abuse and with hooding of salary. They confirmed, Domestic workers reportedly work between nine and nineteen hours a day with very limited rest throughout the day. The finding is consistent with a study that was conducted to examine their problems (Tsehay, 2003). The finding obtained from key informant interview with administrators from South West Shewa Zone women and child affairs and labor and social affairs bureau who revealed that there were no support mechanisms to help illegal immigrants returnees from Middle East countries in Woliso town. This circumstance denoted that the concerned bodies never give an acute attention for those returnees to re-build up their capacity.

\section{Conclusion and Recommendations}

\subsection{Conclusion}

This research finding analyzed the main cause and consequences from the returnees of illegal emigration at Woliso town of south west showa zone. The first major conclusion that can be drawn from this study is that illegal immigrant returnees find themselves in a very difficult and stressful situation while they were living in Middle East countries. The finding further divulged that the consequences of those illegal immigrant returnees usually resulted in physical and psychological injuries, displacement, financial difficulty, loss of self stems. As the study attempted to show the cause of illegal emigration of women, it identified social, economic, political and family problem or disorder.

The study results indicated that Poverty and unemployment together are cited by substantial number of the smuggled migrants as main cause for migration. Next to push factor, unemployment makes the area's people to leave their region or living place or country. In migration the push factors may be low wages, political turmoil, low living standards and the pull factors may be the higher wages, high living standards, decreasing political violence and demand for specific skills set and knowledge.

The variables related to the consequences of illegal emigration included sexual abuse, sexual harassment or abuse, labor exploitation, discrimination of human rights and democratic rights, life, and physical and emotional abuse. The finding revealed that Lack of information and awareness on the prevalence, process and effects of illegal emigration as well as the laws and other available remedies is one of the main causes for the wide prevalence of the practice and the poor status of prosecuting illegal emigrants.

Majority of the returnees demonstrated that pushing factor of illegal emigration are: poverty, separation of family, self sufficiency failure in education, failure to pay dept they took from government and private sector, bad political and religious environment altogether. Besides, most of the victims of illegal emigration interviewed for this study identified economic reasons as the major push factor for their migration followed by separation of family which affects them in many ways. A collected from the study many women who work in Middle Eastern countries illegally emigrated through their families and brokers recruit women in informal manner using a facilitator in which the contracts of employment are altered without the consent of the employee.

\subsection{Recommendations}

Based on the above findings and conclusions made, the following recommendations were forwarded for further intervention.

- Extensive public awareness activities should be carried out to change

This situation;

- Promoting the rights of vulnerable groups: One of the root causes of push factors of illegal emigration is the denial of the rights of the Vulnerable groups; 
- Lack of access to education, information and other social service as well

As harmful traditional practices like early marriage as less value accorded to woman in the society are among the major push factor. Therefore, extensive supports should be made to promote the rights of vulnerable group including access to education;

- Providing guidance and counseling housing and medical services, training and skill up grading etc are very important to rehabilitate and reintegrated victims of illegal emigration;

- Strengthening of diplomatic missions: The establishment and strengthened of diplomatic mission in country were a large number of Ethiopia migrant workers are found is very Important to minimize the abuse and exploitation they are expressing;

- Building the capacity of law enforcement and other government agencies: Most law enforcements and other relevant government agencies are not well occupied in terms of human and resources to properly combat the problem of illegal emigration;

- Gathering evidence, filling and information management related to the status of causes and investigate skill need to be strengthened in order for these institutions to be able discharge their responsibilities efficiently;

- Formulation of relevant policies: The factor that Ethiopia does not have a comprehensive national policy on illegal emigration of women is one of the major problems in combating illegal emigration. This has created confusion on the role of different actors in the coordination of their intervention activities. This intervention activities seems to be sporadic and directed by the more visible and immediate problem without looking at overall problem.

\section{References}

Abiy K. (2008). A rapid assessment of Ethiopian child domestic workers in Addis Ababa. ILO: Geneva.

Anbesse, B., Hanlon, C., Alem, A., Packer, S., and Whitley, R. (2009). Migration and Mental Health: a Study of Low-Income Ethiopian Women Working in Middle Eastern Countries. International Journal of Social Psychiatry, 55(6), 557-568.

Andersson, Lisa. (2014). Migration, Remittances and Household Welfare in Ethiopia. Maastricht: United Nations University.

Braun, V. and Clarke, V. (2006). Using thematic analysis in psychology, Qualitativeresearch in psychology, University of West England, UK (p77-1-101)

Central intelligence agency, (2018). The world fact bookof Ethiopia

Creswell, J. W. (2014). Qualitative inquiry \& research design: Choosing among five approaches. Los Angeles, CA: Sage

Docquier, F. \& Marfouk, A. (2006). International Migration by Educational

Emebet K. (2010). An assessment of the international labor migration situation: The case of female labor migrants in Ethiopia. GENPROM: Geneva.

Emerta Asminew et al., (2010). "International Migration, Remittances and Poverty Alleviation in Ethiopia", Ethiopian Economics Association (EEA) / Ethiopian Economic Policy Research Institute (EEPRI), working paper series, No. $1 / 2010$, Addis Ababa, Ethiopia

Endeshaw, Yoseph, Mebratu Gebeyehu, and Belete Reta. (2006). "Assessment of Trafficking in Women and Children in and from Ethiopia." Addis Ababa: International Organization for Migration.

Fernandez, B., (2013). "Household Help? Ethiopian Women Domestic Workers' Labor Migration to the Gulf Countries." Asian and Pacific Migration Journal 20 (2011): 433-457. . "Traffickers, Brokers, Employment Agents, and Social Networks:

Finlay, L. (2009). Debating phenomenological research methods. Phenomenology \& Practice, 3(1), 6-25.

Jones, Nicola, Elizabeth Presler-Marshall, Bekele Tefera, Guday Emirie, Bethelihem Gebre, and Kiya Gezahegne. (2014). "Rethinking Girls on the Move: The Intersection of Poverty, Exploitation and Violence Experienced by Ethiopian Adolescents Involved in the Middle East 'Maid Trade'." London: Overseas Development Institute.

International labor organization, (2011). Trafficking in Persons Overseas for Labor Purposes: The case of Ethiopian domestic workers, ILO CO, pp. 98, Addis Ababa

International Organization for Migration, (2014). "Community Conversations: Target Irregular Migration from Ethiopia. IOM Special Liaison Office in Addis Ababa, Ethiopia. Accessed online at https://www.iom.int/news/community-conversations-target-irregular- migration-ethiopia.

Kothari,C.R. (2004). Research methodology: Methods and techniques (Rev.ed.).

Daryaganj, New Delhi: New Age International.

Nick Ellison, (2010). Research Method, a practical guide for social science, University of Leed, USA

Philippe Fargues and Nasra M. Shah, (2017). Skilful Survivals: Irregular Migration to the Gulf, Gulf Labour 
Markets and Migration (GLMM) Programme, Gulf Research Center Cambridge,

Seifeselassie Alemayehu, (2014). "Community Conversations Target Irregular Migrationfrom Ethiopia." International Organisation for Migration, August 4, 2014.

Spaan \& Van Moppes, (2006). African Exodus? Trends and Patterns of International Migration in Sub-Saharan Africa. Workin Papers Migration and Development Series, No. 4. Research Group Migration and Development, Radboud University Nijmegen, the Netherlands.

Tsehay, B. (2011). Counter trafficking through information in research and communication strategy. Publisher: City.

United Nations Development Programme, (2009). Human Development report 2009. Overcoming Barriers: Human Mobility and Development. New York: UNDP. 